\title{
VALIDACIÓN DE UN MÉTODO BIOANALÍTICO PARA LA DETERMINA- CIÓN DE OPIÁCEOS, OPIOIDES Y SUS METABOLITOS EN MUESTRAS DE INTERÉS FORENSE, POR CROMATOGRAFÍA DE GASES ACOPLADA A ESPECTROMETRÍA DE MASAS
}

\author{
BIOANALYTICAL METHOD VALIDATION FOR THE DETERMINATION OF OPIATES, \\ OPIOIDS AND ITS METABOLITES IN FORENSIC INTEREST SAMPLES, BY \\ GAS CHROMATOGRAPHY-MASS SPECTROMETRY
}

Meliza Cerón Grisales ${ }^{1 *}$, Eleázar Vargas Mena $^{2}$

\footnotetext{
${ }^{1}$ Química. Facultad de Ciencias Básicas y Tecnologías. Universidad del Quindío

${ }^{2}$ Profesional Especializado Forense. Instituto Nacional de Medicina Legal y Ciencias Forenses. Regional Occidente.

Sede Pereira
}

Recibido: Mayo 15 de 2015

Aceptado: 10 de Julio de 2015

*Correspondencia del autor: E-mail: mely.cg@hotmail.com

\begin{abstract}
RESUMEN
Debido al incremento en casos reportados de crímenes tales como, delitos sexuales y hurtos en personas puestas en estado de indefensión cometidos bajo el efecto de drogas de abuso y evidencias de intoxicaciones accidentales, suicidas y homicidas asociadas al consumo de estas, se hace necesario el desarrollo de técnicas analíticas, selectivas, sensibles y confiables para la determinación de las drogas en muestras biológicas en casos de interés forense. Se validó un método para la determinación de morfina, codeína, 6-acetilmorfina y metadona, en orina y sangre. Los porcentajes de recuperación fueron superiores a $56 \%$ y $63 \%$ para todos los analitos evaluados en orina y sangre respectivamente. Las curvas de calibración fueron lineales con coeficientes de correlación superiores a 0.98 , dentro del rango dinámico asociado a las concentraciones tóxicas o letales reportadas en la literatura. Las CMD y CMC de cada analito se determinaron estadísticamente a partir de las curvas de calibración construidas. La precisión tuvo coeficientes de variación inferiores a $24 \%$ para los analitos. Se obtuvo para codeína en orina $78.9 \%$ de valor predictivo positivo y en sangre $100 \%$, igual que para morfina en orina.

El método desarrollado se aplicó exitosamente para la resolución de casos forenses de accidentes de tránsito, muertes en estudio, determinación de embriaguez no alcohólica y envenenamiento suicida o accidental.
\end{abstract}

Palabras Clave: Opiáceos, opioides, sangre, orina, cromatografía de gases-espectrometría de masas 


\begin{abstract}
Due to the increase in reported cases of crimes such as, sexual offenses and theft in persons placed in a state of helplessness committed under the influence of drugs of abuse and evidences of accidental intoxication, suicide and homicide associated to the consumption of these, is necessary the development of analytical technical, selective, sensitive and reliable for determination of the drugs in biological samples in cases of forensic interest. Was validated a method for determination of morphine, codeine, 6-acetylmorphine and methadone, in urine and blood. The percentages of recovery were higher than 56 y $63 \%$ to all the analytes evaluated in urine and blood respectively. The calibration curves was linear with correlation coefficients higher than 0.98 , within the dynamic range associated to the toxic concentrations or lethal reported in the literature. The CMD and CMC of each analyte were determined statistically from the constructed calibration curves. The precision had coefficients of variation lower than $24 \%$ for analytes. Was obtained for codeine in urine $78.9 \%$ of positive predictive value and blood $100 \%$, as morphine in urine.

The development method was applied successfully for resolution the forensic cases of traffic accidents, deaths on study, determination of non-alcoholic drunkenness and suicide or accidental poisoning.
\end{abstract}

Keywords: Opiates, opioids, blood, urine, gas chromatography-mass spectrometry.

\section{INTRODUCCIÓN}

Los conflictos violentos afectan las poblaciones en los países de bajos y medianos ingresos. La exposición a los conflictos constituye un potencial factor de riesgo para los trastornos mentales y abuso de sustancias tales como los derivados del opio, ya sea de manera ilícita o sin prescripción médica (1).

El término opiáceo se refiere a todos aquellos compuestos que se derivan de la adormidera, Papaver somniferum L, ya sean naturales o semi-sintéticos. Sin embargo, no todos poseen actividad sobre los receptores opioides. Es por ésta razón que no se puede generalizar el uso del término opiáceo u opioide para relacionar los alcaloides estructural o farmacológicamente con la morfina. Los opioides son cualquier tipo de agente endógeno o exógeno que se une a los receptores opioides, produciendo efectos sobre las neuronas por acción sobre la membrana de las células nerviosas.

Los efectos farmacológicos de los opioides incluyen la analgesia, constricción pupilar, euforia, sedación, depresión respiratoria y estreñimiento en dosis terapéuticas (2).

La heroína es generalmente administrada por inyección subcutánea o intravenosa, o menos frecuente por insuflación nasal o fumada. La morfina puede ser ad- ministrada por rutas intravenosa, intramuscular $\mathrm{u}$ oral, mientras que la codeína y la metadona son usualmente administradas vía oral. Esta última es empleada en el tratamiento de la adicción a la heroína (2).

Por medio de la técnica instrumental de Cromatografía Líquida de Alta Eficiencia (HPLC), se puede llevar a cabo el análisis simultáneo de las formas libres y conjugadas, sin necesidad de realizar la hidrólisis de los metabolitos en la matriz de orina. Sin embargo, en la actualidad, la técnica de cromatografía de gases acoplada a un detector de masas está siendo extensamente usada para el análisis de rutina de opiáceos (3) debido al alto costo del equipo de CLAE, el cuál según cotizaciones allegadas al laboratorio tiene un costo de un orden de magnitud por encima.

Uno de los opioides de mayor consumo en Colombia es la heroína, la cual es más bien reciente y menos conocida que otras sustancias. Recientemente el Ministerio de Salud y Protección Social reconoció un preocupante incremento en el consumo de heroína en siete regiones colombianas, entre las cuales se encuentran las tres capitales del Eje Cafetero (4).

Los métodos y técnicas empleados en la investigación forense requieren estar optimizados, estandarizados y validados. Para garantizar la validez y calidad de los ensayos y por ende de los resultados obtenidos, es necesario cumplir con los requerimientos estipulados en 
la NTC-ISO/IEC 17025:2005, así como la selección, uso e interpretación de los ensayos de aptitud establecidos en las guías EURACHEM $(5,6)$.

\section{MATERIALES Y MÉTODOS}

\section{Reactivos y estándares}

Se emplearon estándares de clorhidrato de metadona, codeína monohidratada, sulfato de morfina pentahidratada, clorhidrato de 6-acetilmorfina y clorhidrato de etilmorfina dihidratada, suministrados por Lipomed y Sigma Aldrich. El bicarbonato de sodio, carbonato de sodio y acetato de sodio, fueron adquiridos de Panreac. Los solventes de extracción fueron hexano, acetato de etilo, cloroformo, diclorometano e isopropanol así como los reactivos hidróxido de amonio, ácido acético, adquiridos de JT Baker, $\beta$-glucuronidasa marca Sigma Aldrich y BSTFA+TMCS suministrado por Supelco. El gas de arrastre para el análisis cromatográfico fue helio grado 5 .

\section{Preparación de soluciones}

Se prepararon soluciones stock de los estándares a una concentración de $1000 \mathrm{mg} / \mathrm{L}$. El estándar interno de etilmorfina se preparó a $40 \mathrm{mg} / \mathrm{L}$. A partir de las soluciones stock se tomaron alícuotas para realizar las diluciones necesarias en cada matriz de interés. Se preparó un buffer acetato de sodio $\mathrm{pH}=4.5$ y buffer carbonatos $\mathrm{pH}=8.6$.

\section{Análisis cromatográfico}

Se empleó un cromatógrafo de Agilent Technologies $7890 \mathrm{~N}$ acoplado a un detector selectivo de masas con cuadrupolo 5975C, la columna HP-1 y puerto de inyección spiltless en modo automático. La temperatura del puerto de inyección, fuente de iones y cuadrupolo fueron 200,230 y $150{ }^{\circ} \mathrm{C}$ respectivamente. El programa de horno fue determinado con base en la variación de rampas de temperatura, donde los picos de interés tuvieran buena resolución, separación y la mejor simetría posible. El horno inicialmente tenía una temperatura de $200{ }^{\circ} \mathrm{C} / 1 \mathrm{~min}$, luego se aumentó $6{ }^{\circ} \mathrm{C} / \mathrm{min}$ hasta $310^{\circ} \mathrm{C}$ por $0.5 \mathrm{~min}$. El tiempo total de la corrida fue de 19.8 min y un post run de 6 min hasta $320^{\circ} \mathrm{C}$. El modo de análisis del detector fue SCAN en un rango de masas $(\mathrm{m} / \mathrm{z})$ comprendido entre 30.0 y 550.0.

\section{Extracción líquido-líquido asistida por ultrasoni- do}

Las muestras de sangre y orina fueron obtenidas de donantes sanos, quienes autorizaron la toma en un consentimiento informado, y muestras de interés forense de casos judiciales allegadas a la regional por parte de las unidades básicas y seccionales que cumplen los criterios de cadena de custodia y de recepción en el laboratorio.

Los analitos se extrajeron de la orina como sigue: A 2 $\mathrm{mL}$ de muestra se adicionaron $100 \mu \mathrm{L}$ de etilmorfina $40 \mathrm{mg} / \mathrm{L}$ como estándar interno, $500 \mu \mathrm{L}$ de buffer acetato de sodio $\mathrm{pH}=4.5$ y $100 \mu \mathrm{L}$ de $\beta$-glucuronidasa, se calentó a $60{ }^{\circ} \mathrm{C}$ durante 150 minutos con vortex de $24 \%$, se deja enfriar a temperatura ambiente y luego se adiciona $2 \mathrm{~mL}$ de buffer carbonatos $\mathrm{pH}=8.6$ y $500 \mu \mathrm{L}$ de hidróxido de amonio hasta $\mathrm{pH}$ entre 10 y 11 . La extracción líquido-líquido se realizó adicionando $8 \mathrm{~mL}$ de mezcla de extracción diclorometano:isopropanol $85: 15$. Se sonicó por 20 minutos y centrifugó 5 minutos a $2000 \mathrm{rpm}$.

La fase orgánica se transfirió a un tubo limpio y se evaporó a $60^{\circ} \mathrm{C}$.

A $2 \mathrm{~mL}$ de sangre se adicionaron $100 \mu \mathrm{L}$ de etilmorfina $40 \mathrm{mg} / \mathrm{L}$, seguido de $4 \mathrm{~mL}$ de buffer carbonatos $\mathrm{pH}=8.6$ y $300 \mu \mathrm{L}$ de hidróxido de amonio hasta $\mathrm{pH}$ entre 10 y 11 . Se adicionó $8 \mathrm{~mL}$ de la mezcla acetato de etilo:cloroformo:hexano 70:20:10 para realizar la extracción. Se sonicó y se siguió el protocolo tal como se realiza el procedimiento en orina.

\section{Derivatización}

A los extractos secos se les adicionó $100 \mu \mathrm{L}$ de BSTFA+TMCS (agente derivatizante), seguido de calentamiento a $80^{\circ} \mathrm{C}$ durante 30 minutos con vortex $24 \%$. Las muestras se llevaron al cromatógrafo de gases donde se inyectó $1 \mu \mathrm{L}$ en modo splitless.

\section{Extracción en fase sólida de los analitos en orina}

Para la extracción se emplearon cartuchos narc- 2 . Se tomaron $2 \mathrm{~mL}$ de orina enriquecida con los analitos de interés y se adicionaron $100 \mu \mathrm{L}$ de etilmorfina, 500 $\mu \mathrm{L}$ de buffer $\mathrm{pH}=4.5$ y $100 \mu \mathrm{L}$ de $\beta$-glucuronidasa, se calentó a $60{ }^{\circ} \mathrm{C}$ durante 150 minutos con vortex de $24 \%$, se deja enfriar a temperatura ambiente. Por otra parte el acondicionamiento de la columna de fase sólida se realizó con la adición de $2 \mathrm{~mL}$ de metanol/ hidróxido de amonio (95:5) y $2 \mathrm{~mL}$ de agua desionizada $\mathrm{pH}=4.5$. La muestra ya hidrolizada se cargó a la columna. El lavado de la columna se realizó con 10 
$\mathrm{mL}$ de agua desionizada $\mathrm{pH}=4.5$ y se secó al vacío por 15 minutos. Para la elución se pasaron por la columna $4 \mathrm{~mL}$ de metanol/hidróxido de amonio (95:5). Los extractos se dejaron evaporar a $56^{\circ} \mathrm{C}$. La derivatización se realizó con $100 \mu \mathrm{L}$ BSTFA+TMCS, calentando a $80{ }^{\circ} \mathrm{C}$ durante 30 minutos con vortex $24 \%$. Las muestras se llevaron al cromatógrafo de gases donde se inyectó $1 \mu \mathrm{L}$ en modo splitless.

\section{RESULTADOS Y DISCUSIÓN}

Se obtuvieron los espectros de masas de la biblioteca NIST 08 (figura 1), así como las fragmentaciones para cada analito (tabla 1). El ion de cuantificación para cada analito fue seleccionado, identificando aquella fragmentación que tuviera mayor abundancia en el espectro de masas.

Tabla 1. Fragmentos de masas de cada opiáceo y opioide (7)

\begin{tabular}{cc}
\hline ANALITO & IONES (m/z) \\
\hline Metadona & $309,294,223,165,72^{*}$ \\
Codeína-TMS & $371^{*}, 196,178,146,73$ \\
Etilmorfina-TMS & $385^{*}, 234,192,146,73$ \\
Morfina-2TMS & $429^{*}, 236,196,146,73$ \\
6-Acetilmorfina-TMS & $399^{*}, 340,287,204,73$ \\
\hline *Ion de cuantificación &
\end{tabular}

\section{Validación del método bioanalítico}

\section{- Linealidad del método cromatográfico}

Se construyeron curvas de calibración con cinco niveles concentraciones de los cuatro analitos a partir de la inyección directa de las muestras solubilizadas en metanol y derivatizadas. El análisis de realizó por triplicado. La linealidad fue evaluada con la prueba t-student para el coeficiente de correlación (R2), pendiente de la curva (b) y ordenada al origen (a).

\section{- Idoneidad}

Los parámetros de idoneidad, tiempo de retención $(\mathrm{TR})$, resolución $(\mathrm{R})$, factor de retención $(\mathrm{K})$, factor de simetría (S) y número de platos teóricos $(\mathrm{N})$, se determinaron por medio de la inyección de diez muestras de una mezcla en cada matriz conteniendo cada analito con una concentración igual a $10 \mathrm{mg} / \mathrm{L}$.

Los métodos se considera que son idóneos puesto que los parámetros cumplen con los valores establecidos, siendo el número de platos teóricos superior a 2000, el factor de retención y la resolución superiores a 2 (tabla 2) (8). Sin embargo es importante prestar especial atención ya que no se obtuvieron picos simé-
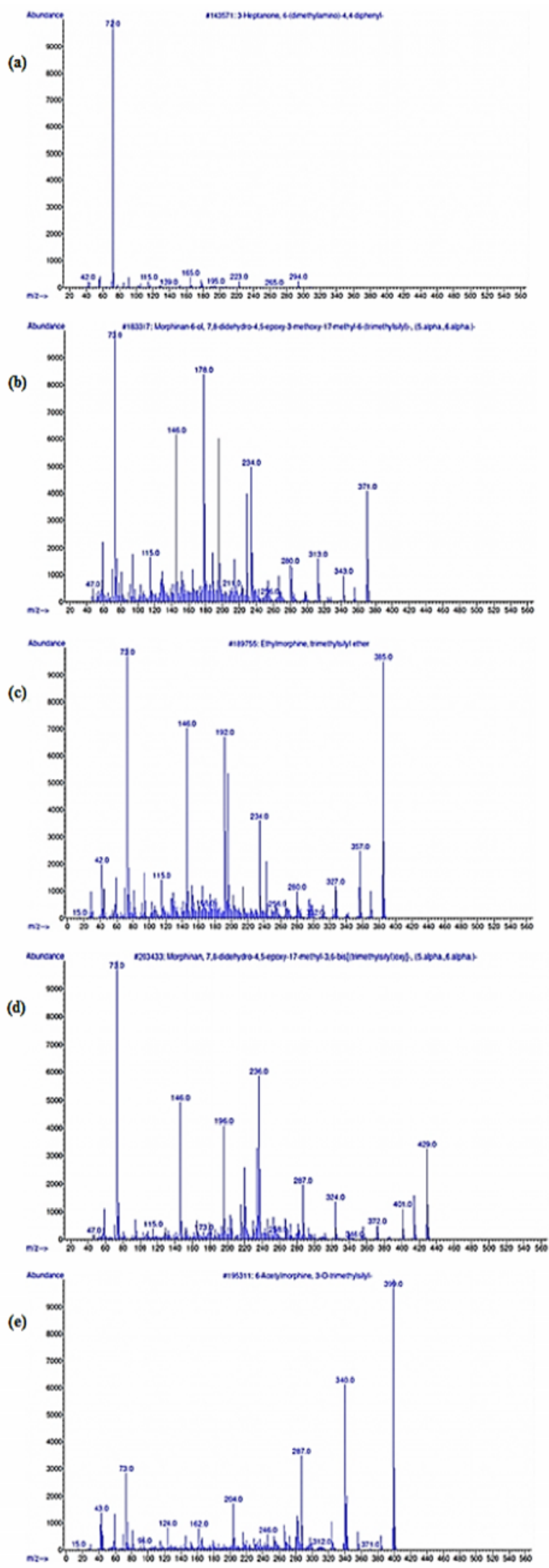

Figura 1. Espectros de masas (a) Metadona (b) CodeínaTMS (c) Etilmorfina-TMS (d) Morfina-2TMS (e) 6-acetilmorfina-TMS 
tricos lo cual dificulta su análisis para propósitos de cuantificación por lo que se pueden presentar errores en la medida de áreas de cada pico cromatográfico y respuestas de cada analito.

\section{- Selectividad}

La selectividad del método fue determinada por medio de la inyección de diez muestras a partir de una solución conteniendo una mezcla de los analitos de interés a una concentración de $10 \mathrm{mg} / \mathrm{L}$ y los principales metabolitos potenciales interferentes que pueden presentarse en casos reales como cocaína, benzoile- cgonina, diazepam, Ácido Delta 9-Tetrahidrocannabinol $(\Delta 9-\mathrm{THC}-\mathrm{COOH})$ y canabinol. Se analizaron los tiempos de retención de los analitos con y sin la presencia de los potenciales interferentes.

Los tiempos de retención de los analitos se modificaron en presencia de los metabolitos potenciales interferentes. Sin embargo la diferencia de los tiempos presentó \%Discrepancia bajos, por lo cual puede considerarse que no existe interferencia sobre la detección de los analitos (tabla 3).

Tabla 2. Parámetros de idoneidad del sistema cromatográfico en orina y sangre

\begin{tabular}{lcccccc}
\hline Matriz & Parámetro & Metadona & $\begin{array}{c}\text { Codeína- } \\
\text { TMS }\end{array}$ & $\begin{array}{c}\text { Etilmorfina- } \\
\text { TMS }\end{array}$ & $\begin{array}{c}\text { Morfina-2TMS } \\
\text { 6-Acetilmorfina- } \\
\text { TMS }\end{array}$ \\
\hline Orina & TR & 6.661 & 10.045 & 10.392 & 10.876 & 11.255 \\
& N & 6831 & 42960 & 107839 & 30320 & 95686 \\
& R & - & 12.607 & 2.165 & 2.518 & 1.881 \\
& S & 1.165 & 0.668 & 1.136 & 0.606 & 1.04 \\
Sangre & K & 5.797 & 9.250 & 9.604 & 10.097 & 10.485 \\
& TR & 6.117 & 9.469 & 9.901 & 10.237 & 10.732 \\
& N & 6902 & 43276 & 29580 & 216281 & 187752 \\
& R & - & 14.048 & 2.087 & 2.090 & 4.702 \\
& S & 1.453 & 0.656 & 0.62 & 0.74 & 0.831 \\
& K & 5.242 & 8.662 & 9.103 & 9.445 & 9.901 \\
\hline
\end{tabular}

$T_{R}$-Tiempo de retención. N-Número de platos teóricos. R-Resolución. S-Factor de simetría. K-Factor de retención. TMS-Trimetilsilil

Tabla 3. Discrepancia de los tiempos de retención en estimación de la selectividad

\begin{tabular}{ccc}
\hline Analito & $\begin{array}{c}\text { Orina } \\
\text { \%Discrepancia }\end{array}$ & $\begin{array}{c}\text { Sangre } \\
\text { \%Discrepancia }\end{array}$ \\
\hline Metadona & 11.84 & 2,92 \\
Codeína-TMS & 9.45 & 3,09 \\
Etilmorfina-TMS & 8.52 & 3,23 \\
Morfina-2TMS & 8.93 & 2,84 \\
6-acetilmorfina- & 8.24 & 2,49 \\
TMS & & \\
\hline
\end{tabular}

\section{- Linealidad}

La linealidad se determinó por medio de la preparación de cinco soluciones en cada matriz con niveles de concentración diferentes, teniendo en cuenta que el menor nivel de concentración alcanzara a tomar el valor de la concentración letal en casos post mortem (9), el análisis se realizó por triplicado.

Observando los resultados obtenidos para cada una de las curvas de calibración se dice que el método y sistema presentan un comportamiento lineal (tabla 4).

\section{- Concentraciones mínimas detectables y cuan- tificables}

Fueron determinadas las concentraciones mínimas detectables (CMD) y cuantificables (CMC) a partir de las ecuaciones de regresión lineal de cada curva de calibración, calculados como la ordenada al origen más 3 y 10 veces la desviación estándar de cada punto $\left(\mathrm{S}_{\mathrm{y} / \mathrm{x}}\right)$ respectivamente.

La cuantificación de los analitos se llevó a cabo en modo SIM.

\section{- Precisión y exactitud}

Se determinó también la precisión del método por medio del coeficiente de variación $(\mathrm{CV})$ y la exactitud con el porcentaje de recuperación de cada uno de los analitos. La recuperación fue determinada por medio de la inyección de tres muestras conteniendo cada uno 

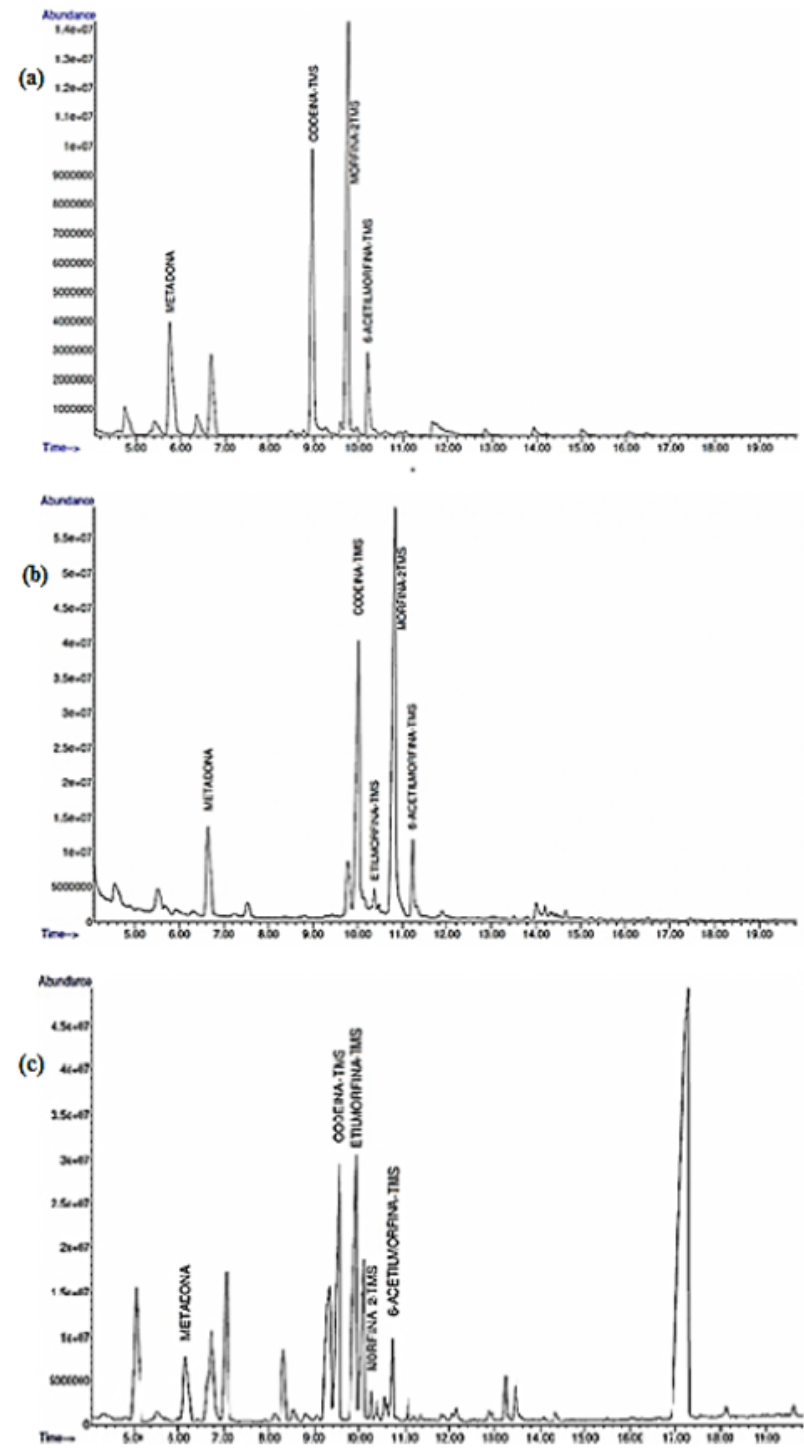

Figura 2. Perfil cromatográfico del sistema idóneo (a) metanol (b) matriz orina (c) matriz sangre

de los analitos a una concentración igual a $2.5 \mathrm{mg} / \mathrm{L}$ en cada matriz y comparando estas respuestas con las obtenidas a dicha concentración en metanol.

Todos los CV cumplen con el valor establecido para considerar la validez del método (tabla 4)

\section{- Precisión intermedia}

La precisión intermedia del método fue hallada, evaluando tres factores: analista-2, día-3 y nivel de concentración-3, donde para este último se tuvo en cuenta que el menor fuera igual a la CMD, el mayor la $\mathrm{CMC}$ y el segundo el promedio de ambas.
Se realizó una prueba $F$ en el programa STATGRAPHICS ${ }^{\circledR}$ CENTURION XVI. Considerando las varianzas entre cada uno de los factores se obtuvo que existen diferencias significativas que generan poca repetibilidad de las respuestas de los analitos si se analizan en diferentes días y por diferentes analistas. Esto se le atribuye a las pruebas de sintonía realizadas en el cromatógrafo antes de cada corrida y a todo el tratamiento por el que debe pasar la muestra. Sin embargo es importante destacar que a pesar de la variabilidad siempre se detectaron los analitos. Por esta razón, para propósitos de cuantificación en sangre se debe realizar una curva de calibración del o los analitos objeto de estudio, la cual debe ser corrida junto con la muestra de interés

\section{- Efecto matriz}

El efecto matriz fue determinado comparando las pendientes (sensibilidad del método) de cada ecuación de regresión lineal de los analitos.

Conociendo el criterio de aceptación para el efecto de matriz, el cual debe oscilar entre 80 y $120 \%$ se tiene que el único analito que cumple con estas condiciones es la codeína-TMS que sufre menos efectos relativos a la matriz en comparación con el resto de los analitos.

\section{- Robustez}

La robustez del método fue determinada por medio del test de Youden y Steiner, realizando por triplicado cada ensayo a una concentración igual a la CMC para cada analito.

Para considerar que el método es robusto, la diferencia entre las respuestas de cada una de las condiciones variables (valor alto $\mathrm{X}$ y valor bajo $\mathrm{x}$ ) debe ser inferior a la desviación estándar multiplicada por la raíz cuadrada de dos, $\Delta \mid \mathrm{X}$-x $\mid<\mathrm{DE} \sqrt{2}$.

De esta manera se obtuvo que cada una de las condiciones variables no mostraron fuerte influencia sobre las respuestas de cada uno de los analitos. Sin embargo el pH de extracción fue el único que evidenció que si se modifica este, las respuestas varían considerablemente. 
Validación de un método bioanalítico para la determinación de opiáceos. Ceron y Vargas.

Tabla 4. Coeficientes para determinar linealidad, precisión, CMD, CMC y recuperación de analitos

\begin{tabular}{cccccccccc}
\hline Matriz & Compuesto & $\begin{array}{c}\text { Conc. } \\
(\mathbf{m g} / \mathbf{L})\end{array}$ & $\mathbf{b}$ & $\mathbf{a}$ & $\mathbf{R 2}$ & $\mathbf{C V}(\mathbf{\%})$ & $\mathbf{C M D}$ & CMC & \% Rec. \\
\hline Orina & Metadona & 0.5 & 3.0991 & 0.2818 & 0.9848 & $<22$ & 0.380 & 2.077 & 56 \\
& Codeína-TMS & 3.2 & 0.9814 & 0.0187 & 0.9918 & $<15$ & 0.182 & 0.778 & 75 \\
& Morfina-2TMS & - & 0.7443 & 0.0402 & 0.9709 & $<19$ & 0.691 & 1.824 & 73 \\
& 6-acetilmorfina-TMS & 1.1 & 0.398 & 0.0035 & 0.9879 & $<14$ & 0.439 & 1.388 & 74 \\
Sangre & Metadona & 1.0 & 17.504 & 0.7931 & 0.9781 & $<15$ & 0.722 & 2.809 & 79 \\
& Codeína-TMS & 0.1 & 1.1866 & 0.0843 & 0.9878 & $<18$ & 0.478 & 2.224 & 72 \\
& Morfina-2TMS & 0.1 & 0.3491 & 0.0186 & 0.9893 & $<24$ & 0.414 & 1.855 & 64 \\
& & 0.004 & 2.7548 & 3.1072 & 0.9927 & $<24$ & 2.419 & 13.327 & 63 \\
\cline { 2 - 9 }$y$
\end{tabular}

$b$-pendiente. $a$-ordenada al origen. CMD, CMC (mg/L). \%Rec -\%Recuperación. Conc-Concentración letal promedio

Tabla 5. Resultados del efecto matriz

\begin{tabular}{ccccc}
\hline Analito & \multicolumn{2}{c}{ Efecto matriz orina } & \multicolumn{2}{c}{ Efecto matriz sangre } \\
& Metanol & Sangre & Metanol & Orina \\
\hline Metadona & 72 & 17 & 407 & 564 \\
$\begin{array}{c}\text { Codeína- } \\
\text { TMS }\end{array}$ & 91 & 82 & 110 & 120 \\
$\begin{array}{c}\text { Morfina- } \\
\text { 2TMS }\end{array}$ & 68 & 213 & 31 & 46 \\
$\begin{array}{c}\text { 6-acetil- } \\
\text { morfina- } \\
\text { TMS }\end{array}$ & 31 & 14 & 219 & 691 \\
\hline
\end{tabular}

Tabla 8. Incertidumbre de la medición en orina y sangre

\begin{tabular}{|c|c|c|c|}
\hline \multirow{2}{*}{ Probabilidad } & \multicolumn{2}{|c|}{ Orina } & Sangre \\
\cline { 2 - 4 } & $\begin{array}{c}\text { Codeína- } \\
\text { TMS }\end{array}$ & $\begin{array}{c}\text { Morfina- } \\
2 \mathrm{TMS}\end{array}$ & $\begin{array}{c}\text { Codeína- } \\
\text { TMS }\end{array}$ \\
\hline $\begin{array}{c}\text { Valor Predictivo } \\
\text { Positivo }\end{array}$ & $78.9 \%$ & $100 \%$ & $100 \%$ \\
\hline $\begin{array}{c}\text { Valor Predictivo } \\
\text { Negativo }\end{array}$ & $100 \%$ & $100 \%$ & $100 \%$ \\
\hline $\mathrm{P}(\mathrm{A} \mid \mathrm{e})$ & $100 \%$ & $100 \%$ & $100 \%$ \\
\hline $\mathrm{P}(-\mathrm{A} \mid \mathrm{e})$ & $0 \%$ & $0 \%$ & $0 \%$ \\
\hline
\end{tabular}

$\mathrm{P}(\mathrm{A} \mid \mathrm{e})$-Probabilidad de verdaderos positivos. $\mathrm{P}(\ulcorner\mathrm{A} \mid$ e)-Probabilidad de verdaderos negativos

Tabla 6. Condiciones variables para la determinación de robustez en orina

\begin{tabular}{|c|c|c|c|c|c|c|c|c|c|c|}
\hline \multicolumn{3}{|c|}{ Condición variable } & \multicolumn{8}{|c|}{ Análisis } \\
\hline Tipo & $\begin{array}{l}\text { Valor alto } \\
\text { (X) }\end{array}$ & $\begin{array}{l}\text { Valor bajo } \\
\quad \text { (x) }\end{array}$ & 1 & 2 & 3 & 4 & 5 & 6 & 7 & 8 \\
\hline Temperatura hidrólisis $\left({ }^{\circ} \mathrm{C}\right)$ & 60 & 30 & 60 & 60 & 60 & 60 & 40 & 40 & 40 & 40 \\
\hline Temperatura derivatización $\left({ }^{\circ} \mathrm{C}\right)$ & 80 & 40 & 80 & 80 & 60 & 60 & 80 & 80 & 60 & 60 \\
\hline Tiempo hidrólisis (h) & 2,5 & 1,5 & 2,5 & 1,5 & 2,5 & 1,5 & 2,5 & 1,5 & 2,5 & 1,5 \\
\hline Tiempo derivatización (min) & 30 & 15 & 30 & 30 & 15 & 15 & 15 & 15 & 30 & 30 \\
\hline Polaridad mezcla solvente & 3,53 & 3,44 & 3,53 & 3,44 & 3,53 & 3,44 & 3,44 & 3,53 & 3,44 & 3,53 \\
\hline Equipo & A & B & A & B & B & A & A & B & B & A \\
\hline $\mathrm{pH}$ extracción & $10-11$ & $3-4$ & $10-11$ & $3-4$ & $3-4$ & $10-11$ & $3-4$ & $10-11$ & $10-11$ & $3-4$ \\
\hline
\end{tabular}

Tabla 7. Condiciones variables para la determinación de robustez en sangre

\begin{tabular}{lcccccccccc}
\hline \multicolumn{1}{c}{ Condición variable } & \multicolumn{1}{c}{ Análisis } \\
\hline Tipo & $\begin{array}{c}\text { Valor alto } \\
(\mathrm{X})\end{array}$ & $\begin{array}{c}\text { Valor bajo } \\
(\mathrm{x})\end{array}$ & 1 & 2 & 3 & 4 & 5 & 6 & 7 & 8 \\
& 3.83 & 4.06 & 3.83 & 3.83 & 3.83 & 3.83 & 4.06 & 4.06 & 4.06 & 4.06 \\
Polaridad mezcla solvente & $10-11$ & $3-4$ & $10-11$ & $10-11$ & $3-4$ & $3-4$ & $10-11$ & $10-11$ & $3-4$ & $3-4$ \\
pH extracción & 20 & 10 & 20 & 10 & 20 & 10 & 20 & 10 & 20 & 10 \\
Tiempo extracción $(\mathrm{min})$ & 100 & 80 & 100 & 100 & 80 & 80 & 80 & 80 & 100 & 100 \\
Volumen derivatizante $(\mu \mathrm{L})$ & 30 & 15 & 30 & 15 & 30 & 15 & 15 & 30 & 15 & 30 \\
Tiempo derivatización $(\mathrm{min})$ & 80 & 40 & 80 & 40 & 40 & 80 & 80 & 40 & 40 & 80 \\
Temperatura derivatización $\left({ }^{\circ} \mathrm{C}\right)$ & $\mathrm{A}$ & $\mathrm{B}$ & $\mathrm{A}$ & $\mathrm{B}$ & $\mathrm{B}$ & $\mathrm{A}$ & $\mathrm{B}$ & $\mathrm{A}$ & $\mathrm{A}$ & $\mathrm{B}$ \\
Equipo & & & & & & & & &
\end{tabular}




\section{- Incertidumbre}

Se determinó la incertidumbre del método empleando el teorema de Bayes por medio del análisis de muestras conteniendo una mezcla de los analitos donde cada uno tenía una concentración igual a CMD.

Se analizaron soluciones conteniendo los analitos y j blancos a los cuales se les realizó todo el proceso de extracción y derivatización.

La incertidumbre para el método en la confirmación de codeína en orina es cero, lo cual indica que el método validado no arrojará falsos positivos, pero podrá arrojar falsos negativos, por tanto resultados interpretados como negativos deberán reportarse como no detectados. Y que la incertidumbre para el método en la confirmación de morfina en orina y codeína en sangre es cero, lo cual indica que el método no arrojará falsos positivos ni falsos negativos (tabla 8).

\section{- Estudio de aptitud (Control interlaboratorial)}

Se analizó una muestra de orina liofilizada proveniente del Programa de las Naciones Unidas.

El ensayo consistió en un Control Interlaboratorial del programa International Quality Assurance Programme (IQAP), International Collaborative Exercises (ICE) del 2014. Biological Specimens (BS) Group. Test Samples Round I. Los resultados de la muestra recibida con código QJH28U y rotulada como BS214 se muestran en la figura 3 .

Los resultados de la muestra en cuanto a la detección de los opiáceos mostró conformidad, por lo cual se dice que el método validado permite la reproducibilidad de los resultados aun en diferentes laboratorios.

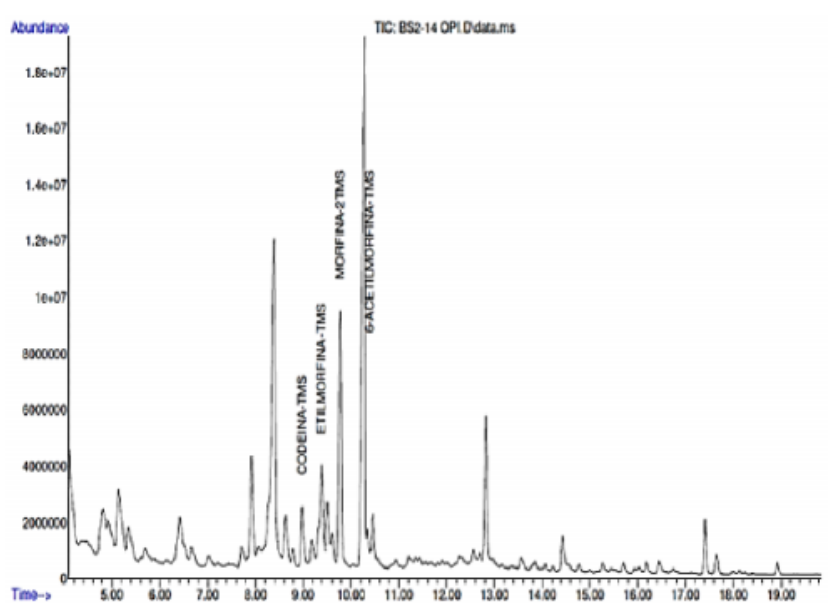

Figura 3. Perfil cromatográfico de control interlaboratorial BS2-14

\section{- Estudio de casos reales}

Caso $\mathbf{N}^{\circ} 1$ : Mujer adulta de 26 años. Ingresada a la sala de urgencias sin signos vitales, luego de ser encontrada por su esposo tendida en la cama con una jeringa enterrada en el brazo conteniendo un líquido oscuro y una bolsa negra.

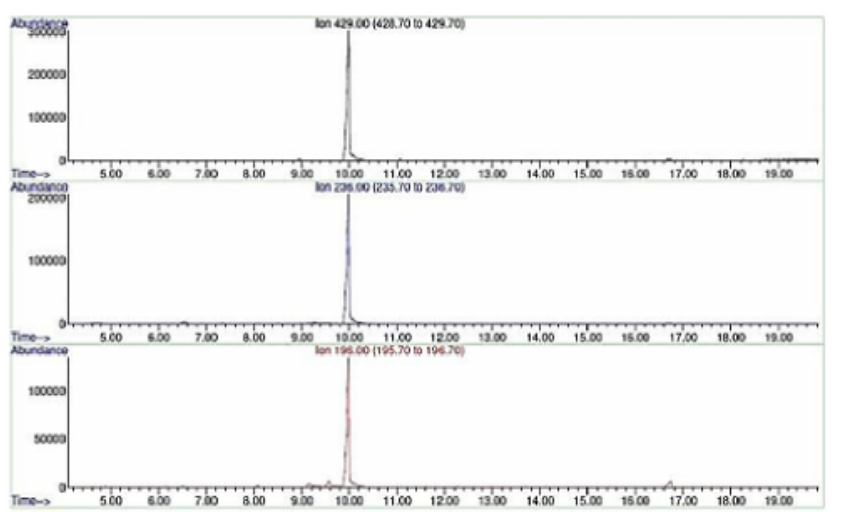

Figura 4. Detección de morfina-2TMS en sangre caso $\mathrm{N}^{\circ} \mathrm{I}$

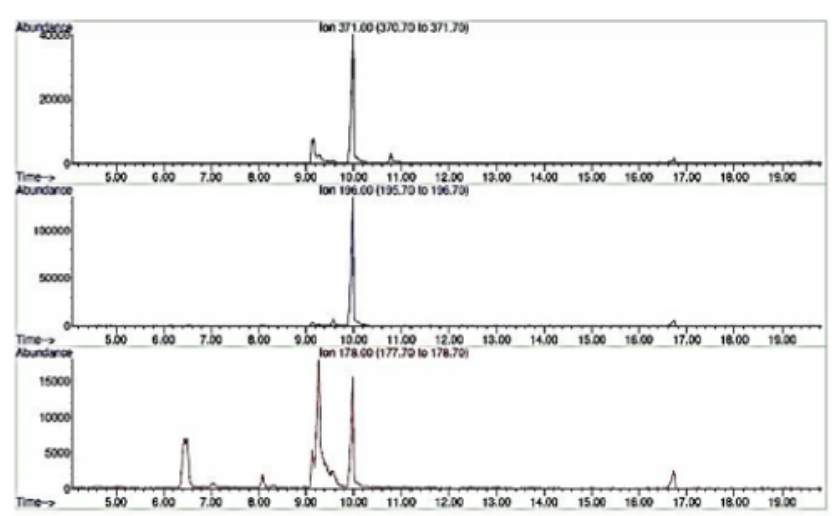

Figura 5. Detección de codeína-TMS en sangre caso $\mathrm{N}^{\circ} 1$

Caso No2: Mujer de 23 años quien se encontraba en un instituto de rehabilitación por consumo de psicoactivos que al ser dada de alta es encontrada en su residencia, sin signos vitales. En uno de los zapatos se encuentran seis papeletas con un polvo blanco. Luego del procedimiento médico legal, se envían al Laboratorio de Química orina, sangre y frotis nasal.

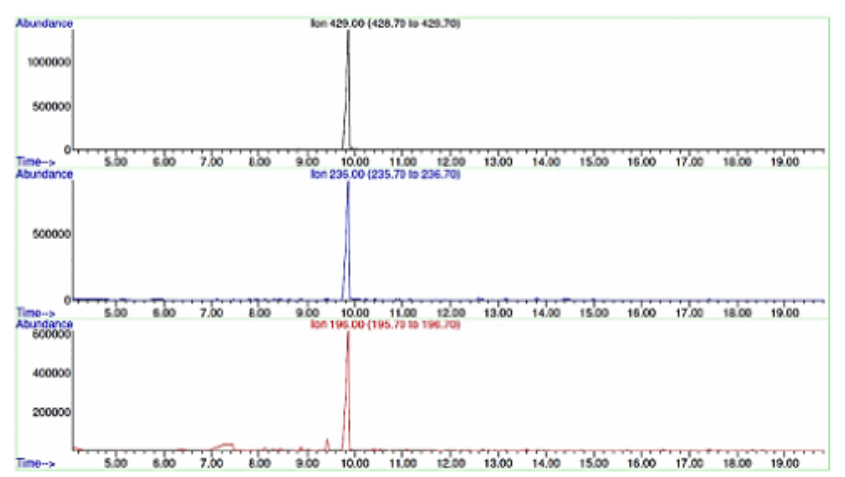

Figura 6. Detección de morfina-2TMS en sangre caso $\mathrm{N}^{\circ} 2$ 
Caso N`3: Joven militar activo de 22 años quien fallece en las instalaciones de una clínica. La investigación preliminar del caso relata que él se encontraba realizando labores propias de su trabajo. El análisis en sangre y orina arrojaron negativo para morfina, codeína, 6-acetilmorfina y metadona.

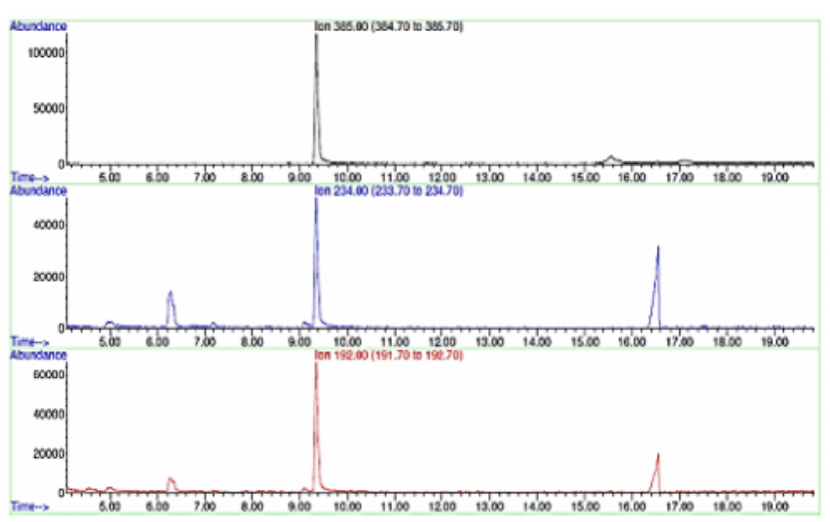

Figura 7. Detección de etilmorfina (estándar interno) en sangre caso $\mathrm{N}^{\circ} 3$

\section{Extracción en fase sólida}

Se realizaron ensayos con extracción en fase sólida (columnas narc-2) de los analitos en orina con el fin de comparar los resultados con los obtenidos en la validación y así plantear recomendaciones. Se obtuvieron resultados de CV inferiores a los arrojados con extracción líquido-líquido, siendo para metadona, codeína-TMS y morfina-2TMS menores al 12, 10 y $7 \%$ respectivamente.

\section{CONCLUSIONES}

Tanto el sistema en orina como en sangre se puede considerar idóneo debido a que cumple con los parámetros establecidos como criterio de aceptación. De la misma manera las curvas de calibración construidas muestran que el método tiene un comportamiento con tendencia lineal con coeficientes de variación inferiores al $25 \%$. El método y sistema en orina y sangre se consideran robustos para condiciones de temperatura, tiempos, equipos y polaridad de la mezcla de extracción. Sin embargo no es robusto cuando se trata de modificaciones en el pH de extracción, ya que este fue una condición que provoca grandes variaciones en las respuestas de los analitos. Finalmente, se comprueba mediante el análisis de casos reales y el control interlaboratorial que el método validado cumple con los requerimientos y propósitos del Laboratorio de Toxicología del Instituto Nacional de Medicina Legal y Ciencias Forenses, Regional Occidente, Sede Pereira.

\section{AGRADECIMIENTOS}

Los autores agradecen al Instituto Nacional de Medicina Legal y Ciencias Forenses, Regional Occidente, Sede Pereira por permitir el acceso a sus instalaciones así como el completo desarrollo del trabajo.

\section{BIBLIOGRAFÍA}

1. Jack H, Masterson AR y Khoshnood K. Violent conflict and opiate use in low and middle-income countries: A systematic review. International Journal of Drug Policy. 2013. 25: 196-203.

2. FENTON, John J. Toxicology: A Case-Oriented Approach. CRC Press LLC, 2002.

3. 3. Suzuki O. Drugs and Poisons in Humans A Handbook of Practical Analysis. Unión Europea: Springer; 2005.

4. República de Colombia. Ministerio de la Protección Social y la Dirección Nacional de Estupefacientes. Estudio Nacional de Consumo de Sustancias Psicoactivas en Colombia, 2008.

5. ICONTEC. Norma Técnica Colombiana NTC-ISO/IEC 17025/2005. Requisitos Generales Para La Competencia De Los Laboratorios De Ensayo Y Calibración. 2005.

6. EURACHEM A focus for analytical chemistry in Europe. Selection, Use and Interpretation of Proficiency testing (PT) Schemes. Second edition. 2011.

7. Maurer HH. Mass Spectral and GC Data of Drugs, Poisons, Pesticides, Pollutants and their Metabolites. Third Edition. Volume 2: Mass Spectra. WILEY-VCH. 2007.

8. Asociación Española de Farmacéuticos de la Industria A.E.F.I. Validación de Métodos Analíticos. Barcelona. 2001.

9. MOFFAT, Anthony C. Clarke's Analysis of Drugs and Poisons. Third Edition. London: Pharmaceutical Press, 2004. 